\title{
Studies on the Rate of Excretion of Aulacophora foviecollis Lucas., the red pumpkin beetle (Coleoptera: Chrysomelidae)
}

Several workers (particularly NAtion and Patton ${ }^{1}$ and RAMSAY ${ }^{2}$ ) have worked on the various aspects of excretory physiology of insects. But no extensive work seems to have been done on the rate of excretion. The rate of excretion of $A$. foviecollis, a phytophagous beetle, causing severe damage to the leaves of pumpkin (Laginaria siceraria Standl.) has been studied.

Material and method. Individuals were collected from the field and kept in cages having green leaves, the peduncles of which were embedded in water kept in petri dishes. Experiments were conducted on both normally fed as well as on $24 \mathrm{~h}$-starved insects separately at various temperatures ranging from 25 to $35^{\circ} \mathrm{C}$. In both conditions, i.e. in normal and starved insects, 10 replicates (1 replicate $=10$ individuals) were conducted. In each replicate individuals were kept in separate petri dishes.

Results and discussion. The beetle's rate of excretion depends on the rate of taking up food. It excretes continuously with intervals of $4-10 \mathrm{~min}$. It commonly excretes all the 3 types of excreta: namely (a) liquid, (b) semi-solid and (c) solid. The first excretion is given out in the form of liquid drops which may be pure urine. After $5 \mathrm{~min}$ of urinal excretion, the beetle produces semi-solid and after 15-20 min solid excreta. The sequence: liquid, semi-solid and solid is not always true, because after a first sequence it can excrete either of the 3 types.

In normally fed individuals the following observations were made. (1) The frequency of solid excretion is higher than that of the other 2 types. (2) The total number of excretions in one replicate is approximately $44 / \mathrm{h}$. (3) The mean interval between excretions is approximately 4-6 min. (4) The rate of excretion depends upon the temperature fluctuation in nature. At $35^{\circ} \mathrm{C}$ the rate was highest. (5) At $35^{\circ} \mathrm{C}$ only solid excreta are produced. This is due to the conservation of water, assisted by the cryptonephridial system of the insect ${ }^{3}$.
In $24 \mathrm{~h}$-starved individuals, which become very sluggish, the following observations were made. (1) Only one type, i.e. solid excreta, is produced. (2) The number of solid excreta in one replicate is approximately $4 / \mathrm{h}$. (3) The mean interval between excretions is about 13$16 \mathrm{~min}$.

It is evident that this phytophagous beetle produces 3 types of excreta if normally fed, whereas starved individuals produce only solid excreta. Furthermore, all normally fed individuals produce excreta and at a higher rate than starved individuals of which only few excrete, probably as a consequence of the lack of food.

Zusammenfassung. Exkretionsrate und Konsistenz der Excreta normal gefütterer und hungertnder Individuen des phytophagen Käfers Aulacophora foviecollis Lucas. wurden untersucht. Alle normal gefütterten Käfer produzieren Excreta, normalerweise flüssige, halbfeste und feste, bei $35^{\circ} \mathrm{C}$ aber nur feste. Die Exkretionsrate gefütterter Käfer ist bedeutend höher als jene von Hungertieren, die entweder keine oder dann nur feste Exkremente ausscheiden.

\section{G. S. SHUkLA and J. P. Singh ${ }^{4}$}

Entomological Laboratory, Department of Zoology,

University of Gorakhpur,

Gorakhpur (U.P., India), 10 September 1969.

1 J. L. Nation and R. L. Patton, J. Insect Physiol. 6, 229 (1961). 2 J. A. Ramsay, J. exp. Biol. 35, 871 (1955).

3 G. S. ShukLA and J. P. SrNGH, Aust. Zool., in press (1969).

4 The authors are indebted to Prof. H. S. CHAUDHRy for providing necessary facilities for the work.

\section{Flow Rate and Lipid Content of Thoracic Duct Lymph after Haemorrhage in Dogs}

During the course of experiments on graded haemorrhage in dogs, it was noticed that after the loss of $45 \%$ of the blood volume the thoracic duct lymph became increasingly cloudy. No change was seen in the lymph of dogs bled $30 \%$ of their blood volume. This suggested a change in lipid content of the lymph in the former group. We have therefore measured the phospholipid, cholesterol and triglyceride concentrations in the thoracic duct lymph of dogs before and after these two grades of haemorrhage.

Method. Five healthy adult male mongrel dogs, which had been splenectomized 2 weeks previously, and which weighed between 15 and $20 \mathrm{~kg}$, were used. Following a $24 \mathrm{~h}$ fast, each dog was anaesthetized as previously described by Furneaux ${ }^{1}$. The thoracic duct of each dog was isolated at its junction with the jugular vein and cannulated with PVC tubing (O.D. $1.52 \mathrm{~mm}$, I.D. $0.86 \mathrm{~mm}$ ) for a distance of $1 \mathrm{~cm}$.

The blood volume of each dog was estimated during an initial $2 \mathrm{~h}$ control period of observation; then $2 \mathrm{dogs}$ were bled $30 \%$, and 3 were bled $45 \%$, of this blood volume via an arterial catheter over a period of $10 \mathrm{~min}$.

Each dog received heparin ( $3 \mathrm{mg} / \mathrm{kg}$ of body weight) $2 \mathrm{~h}$ before, and again $1 \mathrm{~h}$ after the haemorrhage. Lymph was collected for $30 \mathrm{~min}$ before and for three $30 \mathrm{~min}$ periods after the haemorrhage. The volume of each sample was measured, $0.5 \mathrm{ml}$ aliquots were taken, and the remainder was injected i.v. into the dog.

The lymph samples were stored at $-20^{\circ} \mathrm{C}$ until assayed. The methods of ZILVERsmit and DAVIS ${ }^{2}$, VAN HANDEL and Zilversmit ${ }^{3}$, and Brown ${ }^{4}$ were used to measure the phospholipid, triglyceride and cholesterol concentrations.

Results. The results are summarized in Tables I and II. In the 2 moderately bled dogs, the rate of lymph flow following the haemorrhage was unchanged from the control period (see Table I). The phospholipid and cholesterol concentrations were also unchanged, but the triglyceride concentrations fell.

1 R. W. Furneaux, Am. J. vet. Res. 29, 1631 (1968)

2 D. B. Silversmit and A. K. Davies, J. Lab. clin. Med. 35, 155 (1950).

3 E. Van Handel, and D. B. Silversmit, J. Lab. clin. Med. 50, 152 (1957).

4 W. D. Brown, Aust. J. exp. Biol. med. Sci. 37, 523 (1959). 